The Journal of Engineering and Exact Sciences - JCEC, Vol. 05 N. 01 (2019)

journal homepage: https://periodicos.ufv.br/ojs/jcec

doi: https: 10.18540/jcecvl5iss1pp0143-0147

OPEN ACCESS - ISSN: 2527-1075

\title{
DYNAMIC SIMULATION OF AN INDUSTRIAL DISTILLATION
} COLUMN

\author{
FIRMINO, C. K. ${ }^{1}$, DA SILVA,C. A. C. ${ }^{1}$, DA SILVA, M. M. ${ }^{1}$, BIAGGI, P. N. ${ }^{1}$, FERREIRA, N. L. ${ }^{1}$
}

${ }^{1}$ Centro Universitário FEI, Departamento de Engenharia Química, São Bernardo do Campo, São Paulo, Brazil

${ }^{*}$ Corresponding author. Centro Universitário FEI, Departamento de Engenharia Química, São Bernardo do Campo, São Paulo, Brazil, Phone: +55 1143532900 e-mail addressl: libanio@fei.edu.br (N. L. Ferreira).

\begin{tabular}{|c|}
\hline A R T I CLE INFO \\
\hline $\begin{array}{l}\text { Article history: } \\
\text { Received 2018-12-20 } \\
\text { Accepted 2018-03-01 } \\
\text { Available online 2019-03-08 }\end{array}$ \\
\hline $\begin{array}{l}\frac{k e y w o r d s}{1,3 \text {-butadiene }} \\
\text { steady state distillation } \\
\text { dynamic distillation } \\
\text { process control } \\
\text { dynamic simulation. }\end{array}$ \\
\hline
\end{tabular}

\begin{abstract}
A B S T R A C T
This work aims the study of a debutanizer column of a typical petrochemical industry. First a steady state model was built using ASPEN PLUS and then the model was transformed to the dynamic version using ASPEN DYNAMICS. The debutanizer column split a mixture of hydrocarbons into a $C 4$ rich fraction and a $C 5+$ fraction. In the C4 fraction 1-3 butadiene is the desired compound which will be separated in another processing unit. 1-3 butadiene is an important feedstock for the polymer industry. The column dimensions and characteristics and operational conditions where supplied by the company. The first part of the study was the model building and results validation with real data of the industry. Then the model was transformed into the dynamic version for control study purposes. Both open and closed loop studies were performed. The generated curves will be used by the company for control scheme selection purposes.
\end{abstract}




\section{INTRODUCTION}

A Petrochemical industry is a Division of the chemical industry that processes feedstocks from oil like naphtha liquefied petroleum gas and other oil refinery streams. The Brazilian petrochemical industry uses naphtha as the main feedstock. (TORRES, 1997)

Petrochemical products are classified as medium to high value products in the global Market. Petrochemical plants are wide spread all over the world. High competition is a consequence. This makes efficiency the main target for all these companies in order to survive the competitive Market.

Process control has gained growing importance in recent times. Modern tools like dynamic simulation has shown its power to provide studies in a relatively easy way to test different control strategies before its application in the plant. These tools allow the study of control and optimization at the same time if wanted. (SEBORG et al, 2003)

The distillation tower studied in this work is a debutanizer as said earlier. 1-3 butadiene has a high value in the petrochemical Market. Its worldwide demand is more than 9 million metric tons per year. So better control strategies and optimizaton are mandatory for loer production prices (MAGALHÃES, 2008).

\section{TEORY}

\subsection{Distillation}

Distillation is a unit operation widely used in the chemical industry. It is a mass transfer operation used to separate components form a mixture based in their volatilities.

The equipment is a column or tower. Feed is introduced at a intermediary point in the column. This point is previously determined from separation studies At the top of the column heat is withdrawn generating liquid that flows downward. At the bottom of the column heat is added generating vapor that flows upward the column, Is contacting devices the liquid and the vapor flows are mixed together and exchanges mass and heat generating new flows with different compositions. As a result of this process the vapor is enriched with the more volatile compound while the liquid is enriched with the less volatile compound. Two streams are produced: the distillate from the top and the residue from the bottom.

\subsection{Process Control}

According to Riggs (1998), control affects directly the product quality, production rate and utility use. The optimization of a distillation control system assures the product quality and consumption of utilities within equipment limits.

The objective of a distillation column control system is to keep it in steady state. According to Kister (1990), a control system that does not work properly can cause instability in the column and as a result material and economical damages and safety risks as well.

\subsection{Controller tuning}

According to Smith e Corripio (1997), controller tuning is the controller parameters adjusting to match the other characteristics of the other parts of the control loop.

Tuning depends on the process dynamics as well as other process needs. Controller parameters values play important role in the controller action over the manipulated variable in order that the match the set-ponit.

Empirical procedures were first introduced to make the tuning process as easy as possible although none of them could guarantee better controller responses in all disturbance's situations. A fine adjustment is an attemp and error procedure for this purpose (SMITH, CORRIPIO, 1997).

One of the procedures is the controller tuning using the minimum integral error. This procedure is based in the minimum error or deviation between the controlled variable and the set-point. In this method the sum of the error at each instant should be minimized, and this is by definition the integral of the error in time. But the integral of the error can not be minimized directly because the results would be negative. Several correction formulae have been proposed (SMITH, CORRIPIO, 1997).

\section{METHODS}

The column study was made by simulation using the software ASPEN PLUS®. This software is a worldwide standard chemical process simulation. Data used to build and run the model were supplied by the company representing a real case.

\subsection{Steady State Runs}

First of all the column system was studied in steady state mode. Thermodynamic Model: is a set of models used to calculate physico-chemical properties, and transport properties as well. Model selection was based in an Eric Carlson paper. Eric is a well-known ASPENTECH engineer, specialized in thermodynamics (CALRSON, E. 1999).

Feed stream is a mixture of hydrocarbons. According to Carlson best methods for these mixtures are EOS (Equation Of State) Peng-Robinson and Redlich-Kwong-Soave and LeeKesler-Plöcker. Since Lee-Kesler-Plöcker is a seventh degree equation it was discarded due to large mathematical efforts needed. Both other systems were testes to choose the best one.

The column model chosen was RADFRAC, the rigorous distillation model. The column was configured with data supplied by the company as said before. A chosen case was input and run with the two thermodynamic models: PengRobinson and Redilch-Kwong-Soave. Data simulated were compared with plant data.

Conclusion was that either thermodynamic models showed similar results with very little discrepancies when compared with plant data. So Peng-Robinson model were chosen because is the most used model in hydrocarbon simulation studies. 


\subsection{Dynamic Model and Runs}

Column was configured for dynamic simulation with the addition of dimensional data. Other equipment as reboiler, condenser reflux drum and pumps were also configured with dimensional data.

Migration of steady state model to dynamic model is automatic within ASPEN suite. The migrated model was opened in ASPEN DYNAMICS ${ }^{\circledR}$. This procedure insert some controls automatically, Strategy were changed to match plant control strategy. After that changes the model was run to define if proposed tuning was functional. An open loop run was also made in order to search the better conditions for final tuning. To do this disturbances were applies and response measured in graphical form.. The purpose of this study was obtain a transfer function od the process system. A closed loop study was also made with new parameters to check the overall controller performance.

\section{RESULTS AND DISCUSSION}

\subsection{Steady State}

Steady state responses with Peng-Robinson and RedlichKwong-Soave, are shown in table 1.

Tablel 1 - Comparison of steady state resultse.

\begin{tabular}{|c|c|c|c|c|c|c|c|}
\hline & & $\begin{array}{c}\text { Peng- } \\
\text { Robinson }\end{array}$ & SRK & Plant data & $\begin{array}{c}\text { Peng- } \\
\text { Robinson }\end{array}$ & SRK & Plant data \\
\hline & Unity & 4320 & 4320 & 4320 & 4410 & 4410 & 4410 \\
\hline Stream & - & Top & Top & Top & Bottoms & Bottoms & Bottoms \\
\hline Phase & - & Vapor & Vapor & Vapor & Líquid & Líquid & Líquid \\
\hline Temperature & ${ }^{\circ} \mathrm{C}$ & 49,26 & 49,12 & 43,7 & 106,88 & 107,58 & 106,5 \\
\hline Pressure & $\mathrm{kgf} / \mathrm{cm}^{2} \mathrm{~g}$ & 4,02 & 4,02 & 3,97 & 4,36 & 4,36 & 4,37 \\
\hline Mass flow & $\mathrm{kg} / \mathrm{h}$ & 49837,19 & 50223,62 & 52297 & 26630,81 & 26244,38 & 24172 \\
\hline Component B & $\%$ molar & 50,27 & 50,45 & 52,52 & 8,08 & 7,01 & 0,57 \\
\hline
\end{tabular}

Component $\mathrm{B}$ is the main one in the separation process in this. Although the discrepancy in the composition in the bottoms topo compositions are in good agreement. PengRpbinson EOS was chosen..

\subsection{Dynamic runs}

4.2.1 Control Strategies: tuning parameters supplied by company were introduced in the controllers. Disturbances responses were analyzed in stage 44 pressure stage 37 temperature and reflux flow. Figure 1 shows results of a disturbance in the stage 44 pressure setpoint. Distillate flow is ths measured variable.
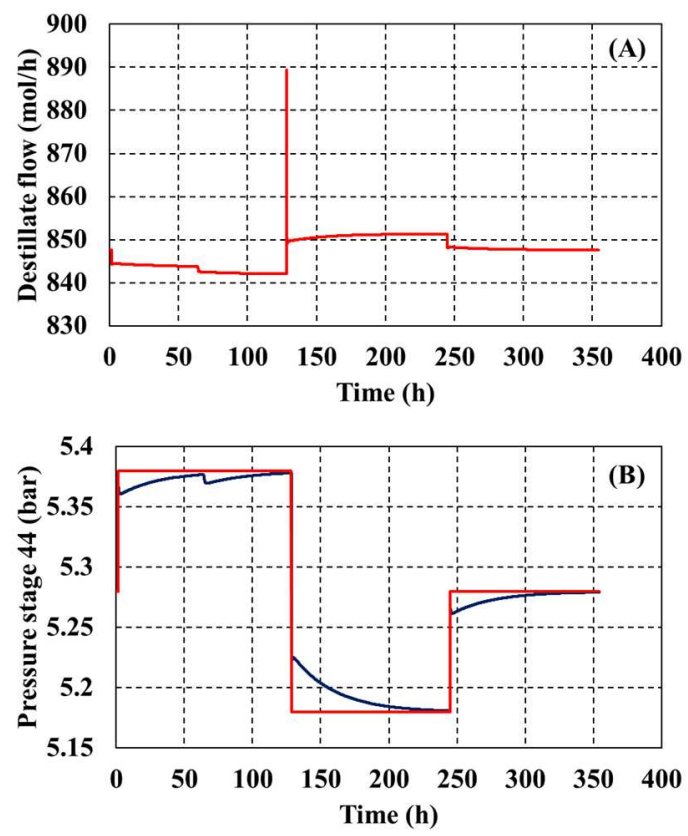

Figure 1 - (A) response of distillate flow; (B) disturbance in the set point and process response
Controller action is too slow so tuning needs to be modified. Controller action in the manipulated variable is low making system response very slow. An error occurs after 125 hours (peak in the graph). Same study was performed for other variables showing unsatisfactory responses. But reflux controller works fine

Open loop studies: for this study sequential step disturbances have been applied. The main target is to verify if system has a linear response and find its transfer function. Disturbnaces were applied in the feed temperature (figure 2 left) and response in figure 2 right is the pressure in stage 44.

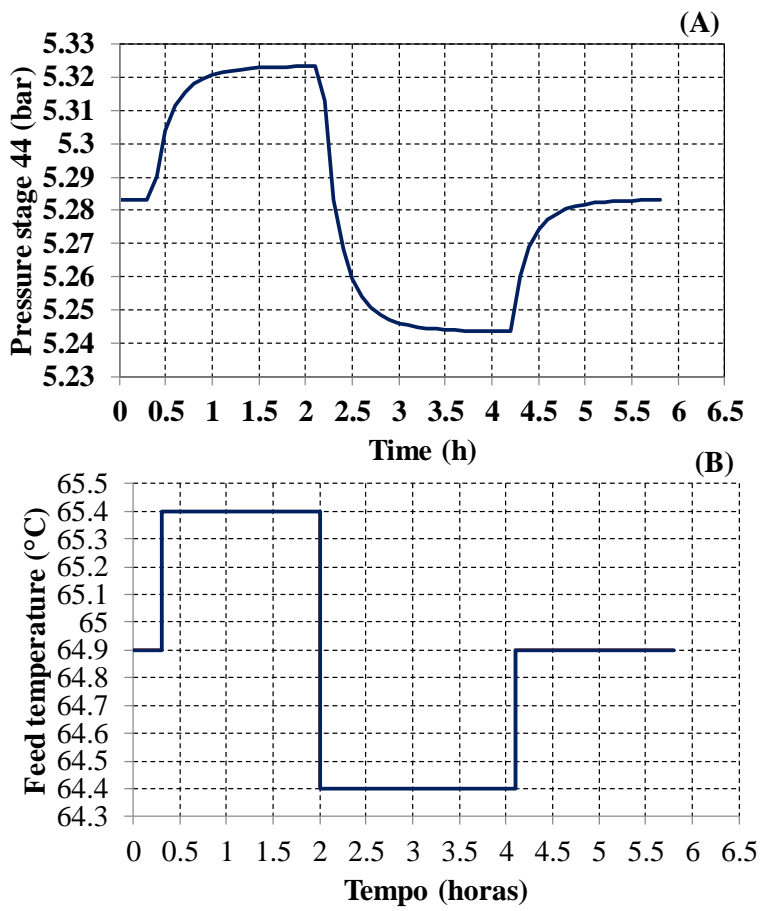

Figura 2 - (A) Process response (pressure in stage 44) ; (B) step in feed temperature . 
With these response curves the systems gains were calculated. Inspections of the results shows that the system is non-linear so one transfer function only it is not suitable for this system. With the use of Smith method it was possible to obtain transfer functions for each disturbance. Results are shown in table 2. Function obtained is of first order with dead time. (equation 1)

$$
G_{p}(s)=\left(\frac{K_{p}}{\tau_{p} s+1}\right) e^{-t_{d} s}
$$

Tablel 2 - Transfer functions for each disturbance.

\begin{tabular}{lccc|}
\hline & $\mathrm{Kp}$ & $\tau_{\mathrm{p}}$ & $\mathrm{t}_{\mathrm{d}}$ \\
\hline Disturbance 1 & 0,0658 & 0,211 & 0,0 \\
Disturbance 2 & 0,0796 & 0,208 & 0,160 \\
Disturbance 3 & 0,0791 & 0,206 & 0,089
\end{tabular}

With the transfer function the method of the integral error (IAE) was applied for the regulatory case in order to obtain controller parameters. This method requires dead time so the first disturbance were not considered.

Table 3 - Controller tuning for each disturbance.

\begin{tabular}{ccc} 
& P & I \\
Disturbance 2 & 16,0 & 0,284 \\
Disturbance 3 & 28,6 & 0,186 \\
\hline
\end{tabular}

Closed loop study: for fine tuning each controller was tuned at a time. Chosen parameters were $\mathrm{P}=16,0$ and $\mathrm{I}=0,284$, referring to the second disturbance. These are low figures e avoid bumps. With these parameters the sequential disturbances were applied. Control action were very fast as compared to previous case. Stabilization time were of about 20 minutes. Taking this responses new teste were done changing controller parameters auntil response were more fast without bumps.

Figure 3 shows feed temperature disturbance and response of the distillate flow. This result refers to the following parameters: $\mathrm{P}=1$ and $\mathrm{I}=15$.

With these parameters controller action is milder without any peaks in the manipulated variable. Disturbances takes about 1 hour to stabilize. There is no over shoot as well.

\section{CONCLUSIONS}

The studied system worked well with both RedilichKowng-Soave and Peng-Robinson EOS. Peng-Robinson EOS was selected dur to its wide use in the hydrocarbon simulation.

During dynamic studies system responded satisfactorily to all applied disturbances. Tuning parameters furnished by the company showed slow responses when applied to disturbances in temperature, although reflux control worked properly with supplied parameters.

In order to obtain better parameters, open loop studies were performed. Results indicated new parameters with shoed better. System showed to be non-linear with dead time. IAE method was used to determine new controller parameter which showed much more better responses when applied.

\section{A C K N O W L E D G M EN T}

To the FEI University Center, to Braskem and to Eng. Lívia Tizzo for the support for the development of the work.
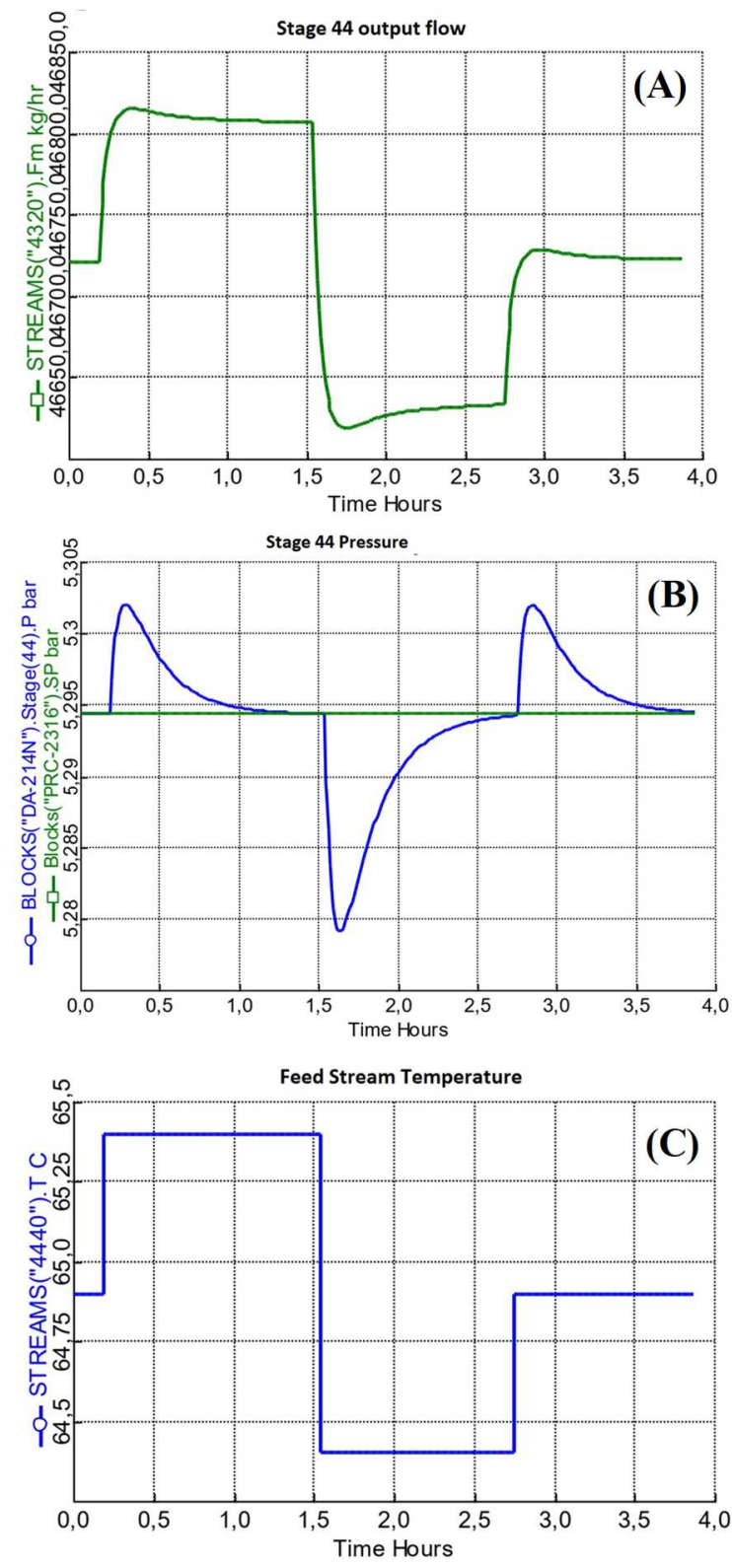

Figure 3 - (A) Response of stage 44 pressure ; (B) feed temperature disturbance; $(\mathrm{C})$ controller action over manipulated variable.

\section{R E F E R E N C E S}

BORGES, M.B; DÍAZ, L. Catalytic Packed-Bed Reactor ConFiguration for BiodieselProduction Using Waste Oil as Feedstock. BioEnergy Research, v. 6, p. 222-228, 2012.

CARLSON, E., Don't Gamble with Physical Properties for Simulations, Chemical Engineering Progress, October pag 35-46, (1996).

KISTER, H.Z. Distillation Operation. McGraw Hill, Nova York, (1990).

MAGAlHÃO, L. R. A. Aumento da demanda global de butadieno. 2008. 35 f. Monografia (Pós-Graduação "Latu Sensu" em Engenharia de Produção) - Universidade

Candido Mendes, Rio de Janeiro, 2008. Disponível em: <http://www.avm.edu.br/docpdf/monografias_publicada s/K206754.pdf >. Acesso em: 18 de maio de 2018. 
RIGGS, J.B. Improve Distillation Column Control, Chemical Engineering Process, outubro, pag. 31-47, (1998).

SEBORG, D.E.; EDGAR, T.F.; MELLICHAMP, D. A. Process Dynamics and Control. 3ed. John Wiley \& Sons, 2010.

SMITH, C. A.; CORRIPIO, A. B. Principles and Practice of Automatic Process Control.

2ed. Estados Unidos: Wiley 1997.

TORRES, E. M. A evolução da indústria petroquímica brasileira. Química Nova, v. 20, p.

49-54, 1997.

Disponível

em:

<http://www.scielo.br/pdf/qn/v20nspe/4982.pdf>.

Acesso em: 18 maio 2018. 